\title{
Reference Scenario for an Advanced Deuterium Power Plant System
}

John Sheffield, Donald Batchelor, and Steven Zinkle. Oak Ridge National Laboratory, and Mohamed Sawan, University of Wisconsin.

\begin{abstract}
The proposal is to make large deuterium (D-D) magnetic fusion power plants in which some (most) of the tritium produced by fusion is removed and stored. This tritium will ultimately decay to helium-3 that will be recycled to supplement the helium-3 produced by fusion. Thus the dominant fusion becomes that of deuterium and helium-3. The level of neutron damage is reduced very substantially from that for a D-T power plant.
\end{abstract}

\section{INTRODUCTION}

The proposal is to make large deuterium (D-D) magnetic fusion power plants in which some (most) of the tritium produced by fusion is removed and stored. This tritium will ultimately decay to helium-3 that will be recycled to supplement the helium-3 produced by fusion. Thus the dominant fusion becomes that of deuterium and helium-3. The level of neutron damage is reduced very substantially from that for a D-T power plant. The tritium could be removed using ion cyclotron waves in a similar manner to that for removing alpha particles from a D-T plasma, as proposed by Chang et al. [1, 2] and tested on TEXTOR [3].

Interestingly, with this scheme it only takes about 25 years before the rate of helium-3 production is sufficient to support a doubling of such plants every decade, with very low tritium content. The importance of this is that the production of $14.1 \mathrm{MeV}$ neutrons is substantially reduced over a standard catalyzed D-D plant and even more so over a D-T plant.

To be specific, if $90 \%$ of the tritium can be removed, the first power plant will average only $5.8 \% 14.1 \mathrm{MeV}$ neutron power, when averaged over 30 years of operation. (5.8\% of total plasma fusion power, any blanket neutron gain is extra). Later generations will get down to less than $4 \%$ of 14.1 MeV neutrons by using surplus helium-3 from earlier power plant operation. Ultimately, in steady state, the 14.1 $\mathrm{MeV}$ fraction will be $3 \%$ of total plasma fusion power.

II ENERGY SPECTRUM OF PRODUCED NEUTRONS:
The energy spectrum of neutrons produced produced in a DD system includes two componenets at $2.45 \mathrm{mev}$ and 14,1 $\mathrm{MeV}$. The relative number of neutrons at these two energies depends on the fraction of tritium removed $\mathrm{f}_{\mathrm{TR}}$ and the fraction of removed tritium that is recycled as He-3 $\left(f_{\text {Rec }}\right)$. In such a system the fusion reactions are represented by the equation below that also indicates the energy carried by the produced neutrons and charged particles.

$$
\begin{gathered}
{\left[4+\left(1-\mathrm{f}_{\mathrm{TR}}\right)+\left(1+\mathrm{f}_{\mathrm{Rec}} \mathrm{f}_{\mathrm{TR}}\right)\right] \mathrm{D}=>} \\
\mathrm{T}(1.01 \mathrm{MeV})+\mathrm{p}(3.02 \mathrm{MeV})+ \\
{ }^{3} \mathrm{He}(0.82 \mathrm{MeV})+\mathrm{n}(2.45 \mathrm{MeV})+ \\
{\left[1-\mathrm{f}_{\mathrm{TR}}\right]{ }^{4} \mathrm{He}(3.5 \mathrm{MeV})+} \\
{\left[1-\mathrm{f}_{\mathrm{TR}}\right] \mathrm{n}(14.1 \mathrm{MeV})+} \\
{\left[1+\mathrm{f}_{\mathrm{Rec}} \mathrm{f}_{\mathrm{TR}}\right]{ }^{4} \mathrm{He}(3.6 \mathrm{MeV})+} \\
{\left[1+\mathrm{f}_{\mathrm{Rec}} \mathrm{f}_{\mathrm{TR}}\right] \mathrm{p}(14.7 \mathrm{MeV})}
\end{gathered}
$$

Based on this, the fraction of fusion energy carried by DD neutrons $(2.45 \mathrm{MeV})$ is given by $2.45 /[43.2-$ $\left.17.6 \mathrm{f}_{\mathrm{TR}}+18.3 \mathrm{f}_{\mathrm{Rec}} \mathrm{f}_{\mathrm{TR}}\right]$ and the fraction carried by DT neutrons $(14.1 \mathrm{MeV})$ is $14.1\left(1-\mathrm{f}_{\mathrm{TR}}\right) /\left[43.2-17.6 \mathrm{f}_{\mathrm{TR}}+18.3 \mathrm{f}_{\mathrm{Rec}}\right.$ $\left.f_{T R}\right]$. The percentage of the fusion power in the neutrons is shown in Table 1 for a range of examples.

Table 1 gives the percentage of fusion power carried by neutrons as a function of the fraction of tritium removed for the cases in which $50 \%$ and all of the tritium removed is recycled as He-3. It is clear that the fraction of energy carried by DT neutrons is reduced significantly as one moves from a fully catalyzed D-D system $\left(\mathrm{f}_{\mathrm{TR}}=0\right)$ to a system with large amount of tritium being removed. This reduction is attributed to the large decrease in the amount of $\mathrm{D}-\mathrm{T}$ reactions taking place. On the other hand, the fraction of energy carried by the DD neutrons does not change or slightly increases (depending on amount of He-3 recycling) as the tritium removal fraction increases due to the decreased total fusion energy. It is clear that significant reduction in energy carried by neutrons is achieved by increasing the fraction of tritium removed. Recycling the He-3 obtained from the decay of the removed tritium results also in reducing the fraction of fusion energy carried by neutrons. However, this effect is not as pronounced as that of removing the tritium from the plasma. 
TABLE 1.

The percentages of power in the neutrons from the plasma for various tritium percentages extracted (50 to 90\%) and for 50\% and $100 \%$ of this tritium returned as helium-3.

\begin{tabular}{|l|c|c|c|c|c|c|c|c|c|c|c|}
\hline $\begin{array}{l}\text { Tritium } \\
\text { Removal }\end{array}$ & $0 \%$ & \multicolumn{2}{|c|}{$50 \%$} & \multicolumn{2}{c|}{$60 \%$} & \multicolumn{2}{c|}{$70 \%$} & \multicolumn{3}{c|}{$80 \%$} & \multicolumn{3}{c|}{$90 \%$} \\
\hline $\begin{array}{l}\text { Percentage } \\
\text { Returned }\end{array}$ & 0 & 50 & 100 & 50 & 100 & 50 & 100 & 50 & 100 & 50 & 100 \\
\hline $\begin{array}{l}2.45 \mathrm{MeV} \\
\text { Neutron \% }\end{array}$ & 5.7 & 6.3 & 5.6 & 6.4 & 5.6 & 6.6 & 5.6 & 6.7 & 5.6 & 6.9 & 5.6 \\
\hline $\begin{array}{l}14.1 \mathrm{Mev} \\
\text { Neutron \% }\end{array}$ & 32.6 & 18.1 & 16.2 & 14.8 & 12.9 & 11.3 & 9.7 & 7.7 & 6.4 & 4.0 & 3.2 \\
\hline
\end{tabular}

\section{REFERENCE TOKAMAK POWER Plant.}

Large tokamak power plants are used to illustrate the approach, because it is possible to use "ITER rules" [4] to develop a consistent system. In reality, at large scale -5000 to $6000 \mathrm{MW}$ thermal - other systems may turn out to be superior. The design of the plant and the general approach is consistent with the Wildcat study [5], calculations by Houlberg and Attenberger [6], and recent calculations by Paul Rutherford [7]. A preliminary calculation suggests that it should be possible to extract $70 \%$ or more of the tritium using radio-frequency waves at $\leq$ $15 \%$ of the electrical output. Several mechanisms have been proposed by which ion cyclotron waves can be employed to produce fluxes of cyclotron resonant particles. C. S. Chang has studied a transport mechanism resulting from asymmetric friction driven by waves with a non-symmetric $\mathrm{k}_{\|}$spectrum. Other studies have considered transport due to the direct effect of RF on particle orbits through perpendicular heating, or coupling of parallel momentum. Particle fluxes from each of the mechanisms scale in a similar way. To obtain a rough estimate of the power required we approximate the RF drive tritium flux as [ref 1 , eq (14)]

$$
\Gamma^{r f}=\frac{\rho_{P}}{\varepsilon_{0}} P_{r f}
$$

where $\rho_{P}$ is the poloidal gyroradius, $\varepsilon_{0}$ is the characteristic tritium particle energy and $P_{r f}$ is the RF power deposition density in the transported particles. We assume that most of the tritium produced is pumped out before it reacts. If that is the case then in steady state the particle flux at each radius must balance the tritium production inside that radius. A more detailed analysis is planned.

\section{A. Example Tokamak parameters}

$\mathrm{R}=9 \mathrm{~m}, \mathrm{R} / \mathrm{a}=2.75, \mathrm{a}=3.27 \mathrm{~m}, \kappa=2.4, \delta=0.65, \beta_{\mathrm{N}}=5$, $\mathrm{q}_{95}=3.1 . \mathrm{B}_{\text {coil }}=14 \mathrm{~T}, \mathrm{~B}=7.31 \mathrm{~T}$, the separation from the toroidal coil to the plasma on the inside is $1.03 \mathrm{~m}$.

$\mathrm{I}=84.5 \mathrm{MA}, \beta=17.7 \%$.

$\mathrm{n}_{\mathrm{e}}=\mathrm{n}_{\mathrm{eo}}\left[1-\mathrm{a}^{2} / \mathrm{r}^{2}\right]^{0.5}$; at start up $\mathrm{n}_{\mathrm{D}}$ is $0.7 \mathrm{n}_{\mathrm{e}}$, at equilibrium it is $0.65 n_{e}$, ,

The average electron density is $2.64 \times 10^{20}$, the

Greenwald limit is $2.52 \times 10^{20}$.

$\mathrm{T}_{\mathrm{e}}=\mathrm{T}_{\text {eо }}\left[1-\mathrm{a}^{2} / \mathrm{r}^{2}\right]^{1.7}, \mathrm{~T}_{\mathrm{i}}=\mathrm{T}_{\text {io }}\left[1-\mathrm{a}^{2} / \mathrm{r}^{2}\right]^{2.0}$.

The average electron temperature is $34 \mathrm{keV}$, while the average ion temperature is $37 \mathrm{keV}$.

At start up Zeff $=1.3$ and at equilibrium it equals 1.4.
Note that $T_{i}>T_{i}$ for $r / a<0.7$. In the central region it is assumed that $30 \%$ of the fast ion power went to the ions and $70 \%$ to the electrons. A large chunk of the ion power is then transferred by collisions to the electrons, because they need to handle the bremsstrahlung and synchrotron and line radiation. It is assumed that, in the center, the ion thermal conductivity is less than that of the electrons (about a factor of five). The pressure due to fast particles is assumed to be $7 \%$ of the total thermal plasma pressure.

\section{B. Power and power fluxes}

The equilibrium charged particle power is 4,600 MW +560 MW of neutrons. With the Wildcat blanket gains, there would be a total of 1,940 MW of neutron generated power.

Bremsstrahlung power is $1,500 \mathrm{MW}$ and synchrotron radiation power is $930 \mathrm{MW}$ at a wall reflectivity of 0.85 . In addition there will be auxiliary power of a few 100 MWs and line radiation ( hopefully mainly from the edge region).

In the equilibrium case, assuming that it would be possible to transport $50 \%$ of the synchrotron radiated power out of the vacuum vessel, the thermal load on the wall would be about $1.95 \mathrm{MW} / \mathrm{m}^{2}$. This is a little high, but the neutron flux would only be $0.3 \mathrm{MW} / \mathrm{m}^{2}$. Furthermore, the 14.1 $\mathrm{MeV}$ flux would be only about $0.1 \mathrm{MW} / \mathrm{m}^{2}$. One can hope that in this situation the wall and shield might survive at least 30 years. When allowance is made for the start up phase, in the first plant, the $14.1 \mathrm{MeV}$ part is on average about 1.5 times higher, but this would still only amount to a $14.1 \mathrm{MeV}$ neutron fluence of $4.5 \mathrm{MW} . \mathrm{y} / \mathrm{m}^{2}$ over thirty years. The total neutron fluence is $10.5 \mathrm{MW} . \mathrm{y} \mathrm{m}^{2}$ over 30 years. In later plants it will be even less.

In a deployment of such power plants, the first plant might run for 3 years with 50\% tritium removal, then 2 years with $75 \%$ removal before reaching the ultimate $90 \%$ tritium removal. With helium-3 recycled the year after it is produced, this system reaches an equilibrium with $50 \%$ of the extracted tritium returned as helium-3 after 15 years. Delaying recycling helium-3 for a year should account for any real-world innefficiencies. In another variant, $90 \%$ of the tritium might be extracted from the start.

At year 16, two new plants could start up using surplus 
helium-3 from the first plant for the first 10 years of their operation. They would operate for 2 years at $50 \%$ tritium extraction and 1 year at $75 \%$ before reaching $90 \%$ extraction.

At year 26, four new plants would start up using surplus helium-3 from the first three plants. They would operate for 3 years at $75 \%$ tritium extraction before going to $90 \%$ extraction. The next eight plants at year 36 and the 16 at year 46 would all start up with $90 \%$ extraction. These plants would operate at slightly lower power than in equilibrium for a few years until their own helium-3 production + surplus helium-3 from earlier plants would allow them to reach the equilibrium state. This deployment is illustrated in table 2 .

TABLE 2.

Possible deployment of power plants to capitalize on helium-3 from tritium decay.

\begin{tabular}{|r|c|c|}
\hline \multicolumn{1}{|l|}{ Year } & $\begin{array}{l}\text { Number of New 3 GWe } \\
\text { Power Plants }\end{array}$ & Total Power GWe \\
\hline 1 & 1 & 3 \\
\hline 16 & 2 & 9 \\
\hline 26 & 4 & 21 \\
\hline 36 & 8 & 45 \\
\hline 46 & 16 & 93 \\
\hline
\end{tabular}

\section{Energy confinement}

The energy confinement time for ITER Elmy H-mode with a multiplier of 1 is 10.6 seconds, sufficient for a total power supporting conduction of 2,280 MW.

\section{Current drive}

Clearly, operation with a high bootstrap fraction will be required, though there should be enough power to provide 5 to $10 \%$ of the plasma current.

\section{E. Tritium storage}

For the example power plant, $102 \mathrm{~kg}$ of tritium would be extracted per year. If this was combined with oxygen to make $\mathrm{T}_{2} \mathrm{O}$ it would have a volume of about 31 liters. Over 30 years, some 14.6 years worth would accumulate. This could be contained in a cubic container 1.65 meters on a side. This container could be housed in the tokamak vault. The helium-3 would be released as gas and collected. Any water vapor or other gases could be frozen out. It would be necessary to separate out the deuterium and a small amount of the tritium from the exhaust gases. This tritium and some of the helium-3 could be used for start up.

\section{NEUTRON DAMAGE TO THE FIRST WALL}

The damage parameters calculated were the atomic displacement rate, the helium production rate, the hydrogen production rate and the total transmutation or burnup rate. The ONEDANT module of the DANTSYS 3.0 discrete ordinates particle transport code system [8] was used to perform the calculations. The most recent version of the International Fusion Energy Nuclear Data Library, FENDL2 [9], was utilized in a 175 neutron energy group structure. The cross section library includes all partial reaction cross sections required to deterime gas production and transmutations. In addition, it includes the damage energy cross sections needed to determine atomic displacements.
The dpa cross sections were determined by Sawan [10] using displacement energies for the constituent elements of the vanadium and steel alloys provided by Greenwood and Smither [11]. For the SiC/SiC composite, the average displacement energies for the $\mathrm{Si}$ and $\mathrm{C}$ sublattices were taken to be 40 and $20 \mathrm{eV}$, respectively [12]. Calculations show a substantially reduced amount of annual neutron damage (both displacements per atom and helium and hydrogen production) as the tritium is removed and recycled as helium-3. In fact, for more than $70 \%$ tritium removal and high helium-3 recycling, the damage levels approach those of a fast fission reactor. This is illustrated in figure 1 for the case of a 9Cr-2WVTa ferritic steel alloy wall/shield. Similar results were obtained for a $\mathrm{SiC} / \mathrm{SiC}$ composite and a $\mathrm{V} 4 \mathrm{Cr} 4 \mathrm{Ti}$ vanadium alloys. By the same token, the amount of induced radioactivity over the plant lifetime will be less.

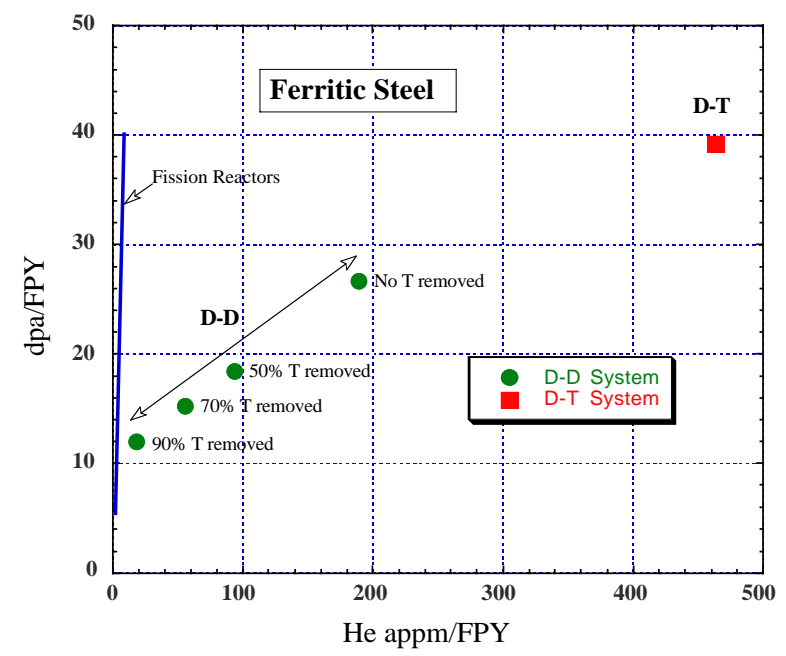

Figure 1. Neutron damage per year for equivalent D-D (tritium suppressed, 100\% helium recycling) and D-T power plants ( D-T plant operating at a neutron wall loading of $5 \mathrm{MW} / \mathrm{m}^{2}$ ), compared to typical fast fission reactors.

\section{COMMENTS}

The point of this paper is not to claim that this is the absolute right way to do a D-D system with tritium removal and helium-3 recycling, but to illustrate the kind of opportunities that exist. Clearly, the issue of disruptions in tokamaks must be solved before one would dare build an 84 Mega-Ampere machine. Nevertheless it is very encouraging that within ITER rules it is possible to conceive of such a device without having to push the various boundaries unreasonably $\mathrm{H}=1, \beta_{\mathrm{N}}=5$, and a density only a few percent above the Greenwald limit. It could be that some other configuration will turn out to be superior e.g, the stellarator, stellarator tokamak hybrid or FRC.

Interestingly, after a time, the rate of surplus helium-3 production becomes quite substantial. This could permit the introduction of systems with higher fractions of helium-3 for specific purposes e.g., in sensitive countries or for space propulsion. 
Proliferation is obviously another issue that needs to be addressed.

\section{ACKNOWLEDGEMENTS}

This manuscript has been authored by a contractor of the U.S. Government under contract No. DE-AC0500OR22725. Accordingly, the U.S. Government retains a nonexclusive, royalty-free license to publish or reproduce the published form of this contribution, or allow others to do so, for U.S. Government purposes.

\section{REFERENCES}

[1] C.S.Chang, "Control of Energetic Ion Confinement by Ion Cyclotron Range of Frequency Waves", Phys. Fluids B 3 (1), 259, 1991.

[2] C.S.Chang et al., "Theory of Energetic Ion Transport Induced by Waves of Ion Cyclotron Range of Frequencies in a Tokamak Plasma", Phys. Fluids B 3 (12), 3429, 1991.

[3] R.Koch et al., "Interaction of ICRF Waves with Fast Particles on TEXTOR", Plasma Phys. Control. Fusion 37, A291, 1995.

[4] "ITER Physics Basis", Nuclear Fusion, Volume 39, number 12, 1999.

[5] K. Evans Jr., et al "Wildcat: a Catalyzed D-D Tokamak Reactor”, ANL/FPP/TM-150, 1981.

[6] S.Attenberger and W. Houlberg, "Plasma Physics Sensitivity Analysis of Catalyzed D-D Operation in Tokamaks", Proc. Fourth Meeting, the Technology of Controlled Nuclear Fusion, King of Prussia, PA, Oct 14-17, 1980, volume 111, 941, July 1981.
[7] P.Rutherford, private communication October, 2000.

[8] R.E. Alcouffe et al., "DANTSYS 3.0, A Diffusion Accelerated Neutral Particle Transport Code System", LA-12969-M, Los Alamos National Laboratory(June 1995).

[9] M. Herman and H. Wienke, "FENDL/MG-2.0 and FENDL/MC-2.0, The Processed Cross-Section Libraries For Neutron-Photon Transport Calculations," Report IAEA-NDS-176, International Atomic Energy Agency (March 1997).

[10] M.Sawan, S.Zinkle, and J.Sheffield, "Assessment of Impact of Tritium Removal and He-3 Recycling on Structure Damage Parameters in a D-D System", University of Wisconsin Fusion Technology Institute Report UWFDM-1157, August 2001.

[11] L. Greenwood and R. Smither, Proc. of the Advisory Group meeting on Nuclear Data for Radiation Damage Assessment and Reactor Safety Aspects, 12-16 October 1981, IAEA, Vienna (1981).

[12] S.J. Zinkle and C. Kinoshita, "Defect production in ceramics", J. Nucl. Mater. 251 (1997) 200-217. 